\title{
Comparison of Efficacy of Laryngeal Mask Airway and Intersurgical- Gel Supraglottic Airway Device During General Anesthesia in a Tertiary Care Hospital
}

\author{
Muhammad Saqib Butt', Noor un Nisa ${ }^{2}$, Ghulam Mustafa', Hasham Khan ${ }^{3}$ \\ ${ }^{1}$ Senior Registrar, Department of Anesthesia, Dr. Akbar Niazi Teaching Hospital, Islamabad \\ 2 Senior Registrar, Department of Anesthesia, Shaikh Zayed Hospital, Lahore \\ ${ }^{3}$ Senior Registrar, Department of Urology, Dr. Akbar Niazi Teaching Hospital, Islamabad
}

\section{A B S T RACT}

\begin{abstract}
Background: Upper airways collapse during anesthesia is a common issue faced by anesthetists. Air way maintenance is an essential component of general anesthesia. Laryngeal mask airway and Intersurgical-gel (i-gel) air way devices are new advances in general anesthesia. Present study aims to compare the ease of insertion and hemodynamic response of i-gel supraglottic and laryngeal mask airway (LMA).

Material and Methods: A Randomized Clinical trial was conducted at the Department of Anesthesia, Shaikh Zayed Hospital, Lahore. Study duration was 6 months (June 2014- December 2014). A total of 60 patients were selected through non-probability consecutive sampling. Ethical approval was taken from ethical review board of Sheikh Zayed Hospital and informed written consents were taken from all the participants. Patients were randomly divided into two groups using lottery method. Group A was given laryngeal mask airway device while group B patients were provided with i-gel supraglottic device during anesthesia. Patients were compared for ease of insertion and hemodynamic parameters. Data was analyzed using SPSS version 24. Chi-square and t-test were applied and $p$-value $\leq 0.05$ was considered statistically significant.
\end{abstract}

Results: A total of 60 patients were included in study. Mean age of patients was $35.2 \pm 11.7$ years in LMA group and $36.7 \pm 13$ years in i-gel group. Group B had lower number of insertion attempts $(p=0.01)$ and high insertion satisfaction $(p=0.4)$ as compared to group A. However, process failure and bleeding rate was found to be slightly higher in group B ( $16 \%$ and $13 \%$ respectively) as compared to group A ( $p>0.05)$.

Conclusion: i-gel supraglottic device is a successful alternative option in terms of ease of insertion and less hemodynamic response as compared to laryngeal mask airway during general anesthesia.

Key words: General anesthesia, Laryngeal mask airway, l-gel supraglottic device

\begin{tabular}{lll}
\hline Authors' Contribution: & Correspondence: & Article info: \\
1,2 Conception, synthesis, planning of & Muhammad Saqib Butt & Received: April 16, 2019 \\
research and manuscript writing & Email: drsaqibbutt@hotmail.com & Accepted: August 23, 2019
\end{tabular}

Interpretation, discussion, 3, Active

Accepted: August 23, 2019

participations in data collection and Data

analysis.

Cite this article. Butt MS, Noor un Nisa, Mustafa G, Khan H. Comparison of Efficacy of Laryngeal Mask Airway and Intersurgical-Gel Supraglottic Airway Device During General Anesthesia in a Tertiary Care Hospital. J Islamabad Med Dental Coll.2019; 8(3):151-155.

doi: 10.35787/jimdc.v8i3.331

\section{Introduction}

Upper airways collapse during anesthesia is a common issue faced by anesthetists, worldwide. ${ }^{1}$ Proportions of deaths associated with airways complication during anesthesia are increasing significantly from $1990 .{ }^{2}$ Royal College of Anesthetists and Difficult Airway Society reported that airway related deaths are $7 / 1,000,000$ in United Kingdom (UK). ${ }^{3}$ Mortality rate due to air ways collapse during anesthesia is $2.6 \%$ in Togo. ${ }^{4}$ Prevalence of anesthesia related complications in Pakistan is $5.5 \%$ with more than $30 \%$ attributed to respiratory 
complications. ${ }^{5}$ Upper airway obstruction hallmark includes diminished or absent airflow (presence of continued respiratory effort).

Air way obstruction could be complete or partial. Literature reports that patients with supralaryangeal obstruction had snoring as most common sign while patients with perilaryngeal obstruction had inspiratory stridor as a common sign. ${ }^{6}$ Prevention and management of upper airway obstruction include anatomical positioning and posture, Continuous positive airway pressure (CPAP), heliox, tracheal tubes and airways aids. ${ }^{7}$

I-gel supraglottic airway is anatomically designed as a mask (composed of gel like thermoelastic elastomers). This single used device is featured for separation of respiratory and gastrointestinal tract. The device allows gastric tubes to pass in stomach. Stability of device during insertion is associated with tensile properties of i-gel bowel. I-gel becomes narrow and longer upon sliding under pharyngo-epiglottis folds. Proximal bowl ridge catches tongue base and helps to prevent device from moving upward out of position. ${ }^{8} \mathrm{~A}$ laryngeal mask airway (LMA) is another supraglottic airway device initially developed by Dr. Archi Brain (British Anesthesiologist). ${ }^{9}$ LMA is shaped like an endotracheal tube at the proximal end and this tube connects to an elliptical mask at the distal end. LMA attributes to less gastric distention and reduce risk of aspiration. ${ }^{10}$

Revi et al reported that i-gel is a successful alternative to LMA in terms of shorter duration of insertion and less hemodynamic response during general anesthesia.. ${ }^{11}$ Radhika et al reported that LMA and i-gel did not cause any significant change in hemodynamic status of patients. However, i-gel insertion is easier and rapid as compared to LMA. ${ }^{2}$ Limited data is available on efficacy of $\mathrm{i}$-gel and LMA efficacy in Pakistan. The objective of the present study was to compare the ease of insertion and hemodynamic response of i-gel supraglottic device and laryngeal mask airway (LMA).

\section{Material and Methods}

A randomized clinical trial was conducted at department of Anesthesia Shaikh Zayed Hospital, Lahore. Study duration was 6 months from November 2015 to April 2016. Sample size was calculated with $80 \%$ power of study, confidence interval $95 \%, \mu 1=27.1 \pm 16.7, \mu 2=$ $14.93 \pm 4.6$, standard deviation 16.7 using sample size calculation formula for clinical trials. ${ }^{13,14}$ Calculated sample size was 30 patients in each group. Recruitment of patients was done through non probability consecutive sampling. Patients with age 18-70 years, both genders, weighing $30-100 \mathrm{~kg}$, American Society of Anesthesiologists (ASA) I and II, Mallampati grades (I and II), patients undergoing elective surgery (under general anesthesia $\leq 30$ minutes), fasting patients (>6 hours' solids and $>2$ hours' liquids other than milk) and patients with non-symptomatic regurgitation were included in the study. Exclusion criteria included obesity, pregnancy, history of cardiovascular and renal diseases, gastroesophageal reflux diseases, chain smokers $(>40$ cigarettes/day), drug abusers, trauma (thoracic, abdominal, orofacial, head and neck) and anticipated difficult intubation. Ethical approval was taken from ethical review board. Consent forms were taken from all the participants. Patients were randomly divided into two groups using lottery method. In group A, laryngeal mask airway and in group B,i-gel was used for intraoperative maintenance of airway. The patients were pre-medicated with Midazolam 2.5mg intravenous (I/N) 15 minutes before shifting to operation theatre. Patients were preoxygenated for three minutes with $100 \%$ oxygen. Propofol $1 \% 2 \mathrm{mg} / \mathrm{kg} \mathrm{I} / \mathrm{V}$ were given at induction. I- gel and LMA was lubricated with distilled water. After 1 minute of ventilation with Oxygen and sevoflurane using a face mask, LMA or an l-gel was placed in peri laryngeal area. Anesthesia was maintained with $\mathrm{O}_{2}$, sevoflurane and with intermittent positive pressure ventilation (IPPV). Injection Tramadol $1.5 \mathrm{mg} / \mathrm{kg}$ was given for analgesia. Group A and $B$ were assessed for ease of insertion and hemodynamic status of LMA and I-gel. Ease of insertion was measured in terms of mean insertion time, insertion attempts, bleeding and failure status. Hemodynamic response was measured through physical assessment with ASA grading, airways assessment through Mallampatti class (MPC) grading, mean heart rate, mean systolic and diastolic blood pressure and mean arterial pressure. Data was analyzed using SPSS version 24. Descriptive statistics, mean \pm standard deviation and frequency and 
percentages were calculated. Independent $t$ test and Chisquare test were applied for comparison. P-value $\leq 0.05$ was considered statistically significant.

\section{Results}

A total of 60 patients were included in the study (1:1 randomization, 30 patients in each group). Mean age of patients in group $A$ was $35.2 \pm 11.7$ years and mean age of patients in group $B$ was $36.7 \pm 13$ years. There were 15 $(50 \%)$ males and $15(50 \%)$ females in group $A$. There were $10(33 \%)$ males and $30(67 \%)$ females in group B. ASA grading and MPC grading were different in Group A and Group B. Number of 2 insertion attempts were significantly lower in group $B$ as compared to LMA patients ( $10 \%$ versus $23 \%, p=0.01$ ) (Table I). Insertion satisfaction was higher in group $B(93 \%, p=0.424)$. Moreover, failure and bleeding rate were slightly high $(16 \%$ and $13 \%)$ in group $B$, however no statistical significance was found ( $p>0.05)$ (Figure 1).

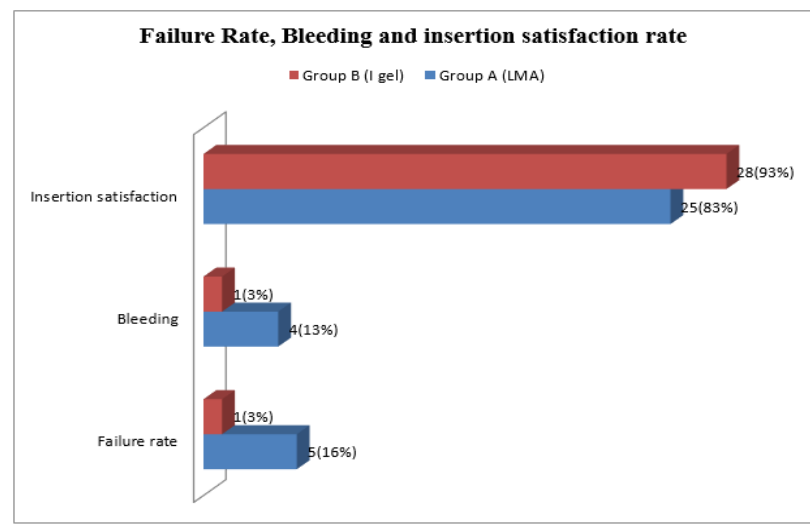

Figure 1: Comparison of failure rate, bleeding episodes and insertion satisfaction rate between two groups $(n=60)$.

\begin{tabular}{|c|c|c|c|c|}
\hline \multicolumn{5}{|c|}{$\begin{array}{c}\text { Table I: Comparison of ASA, MPC grading and number of } \\
\text { attempts in LMA and lgel Group }(n=60)\end{array}$} \\
\hline ASA grading & $\begin{array}{c}\text { Group A } \\
n=30 \\
n(\%)\end{array}$ & $\begin{array}{c}\text { Group B } \\
\text { n=30 } \\
n(\%)\end{array}$ & $\begin{array}{l}\text { Total } \\
\mathrm{n}(\%)\end{array}$ & $\begin{array}{c}P \text { - } \\
\text { value }\end{array}$ \\
\hline ASA grade I & $10(33)$ & $20(67)$ & $30(50)$ & 0.01 \\
\hline ASA grade II & $20(67)$ & 10(33) & $30(50)$ & \\
\hline \multicolumn{5}{|l|}{ MPC grading } \\
\hline Grade I & 12(40) & $18(60)$ & $30(50)$ & 1.00 \\
\hline Grade II & $18(60)$ & $12(40)$ & $30(50)$ & \\
\hline \multicolumn{5}{|c|}{ Number of attempts } \\
\hline One attempt & $23(77)$ & $27(90)$ & $50(83)$ & 0.01 \\
\hline Two attempts & $7(23)$ & $3(10)$ & 10(17) & \\
\hline Total & $30(50)$ & $30(50)$ & $60(100)$ & \\
\hline
\end{tabular}

Insertion time was significantly low in group $B(p=0.02)$. No statistical difference was found in hemodynamic parameters including heart rate, systolic blood pressure, diastolic blood pressure and Mean arterial pressure between groups $A$ and $B$ (Table II).

\begin{tabular}{|c|c|c|c|c|}
\hline Variables & $\begin{array}{c}\text { Group A } \\
(n=30) \\
\text { LMA } \\
\text { Mean } \pm \text { SD }\end{array}$ & $\begin{array}{c}\begin{array}{c}\text { Group B } \\
(n=30) \\
\text { l-gel }\end{array} \\
\text { Mean士SD }\end{array}$ & $\begin{array}{c}\mathrm{T} \\
\text { value }\end{array}$ & $\begin{array}{c}P \\
\text { value }\end{array}$ \\
\hline $\begin{array}{l}\text { Ease of insertion } \\
\text { Insertion time; } \\
\text { (seconds) }\end{array}$ & $10.67 \pm 1.6$ & $9.5 \pm 0.7$ & 2.18 & 0.02 \\
\hline \multicolumn{5}{|c|}{ Hemodynamic response } \\
\hline $\begin{array}{l}\text { Heart rate; } \\
\text { beats/min }\end{array}$ & $80.9 \pm 14.9$ & $78.17 \pm 11.2$ & 1.23 & 0.72 \\
\hline $\begin{array}{l}\text { Systolic blood } \\
\text { pressure }(\mathrm{mmHg})\end{array}$ & $114.4 \pm 16.9$ & $111.40 \pm 18.4$ & 2.15 & 0.83 \\
\hline $\begin{array}{l}\text { Diastolic blood } \\
\text { pressure }(\mathrm{mmHg})\end{array}$ & $65.4 \pm 12$ & $63 \pm 11.6$ & 1.98 & 0.88 \\
\hline $\begin{array}{l}\text { Mean arterial } \\
\text { pressure }(\mathrm{mmHg})\end{array}$ & $83.5 \pm 11$ & $81.10 \pm 9$ & 2.16 & 0.83 \\
\hline
\end{tabular}

\section{Discussion}

Adequate ventilation availability is a major responsibility of anesthesiologist. Several supraglottic devices are available but most common are laryngeal mask airway and i-gel supraglottic airway. ${ }^{15}$ These devices are used in surgeries requiring general anesthesia and are used to avoid changes in hemodynamic responses due to endotracheal intubation in patients undergoing airway maintenance during anaesthesia. ${ }^{16}$

Majority of group B (i-gel) patients in our study had grade I ASA scores as compared to Group A (LMA) patients. Reza et al also reported that reduction in ASA grading was found in i-gel supraglottic patients as compared to patients treated with LMA $(p=0.00) .{ }^{17}$

In the present study, most of the patients in LMA group $(60 \%)$ had MPC grade II for air way maintenance, however, in i-gel group majority of patients $(60 \%)$ had MPC grade I for airway maintenance $(p=0.60)$. An et al. ${ }^{18}$ and Kapoor et al..$^{19}$ reported findings contrasting to our study. They reported majority of patients with MPC I for airway maintenance in i-gel group as compared to LMA group. 
In the present study, number of insertion attempts were significantly lower in i-gel group as compared to LMA patients $(10 \%$ versus $7 \%, p=0.01)$. Other researchers have reported much higher percentages of success in their studies. For example, Fujiwara et al reported that success rate in first attempt with i-gel was 100\%, however, success rate in first attempt with LMA was $84 \% .{ }^{20}$ Similarly, Acharya et al reported that ease of insertion is higher in i-gel ${ }^{\mathrm{TM}}$ as compared LMA classic ${ }^{\mathrm{TM}}$ $(p<0.05){ }^{21}$

In the current study, among all patients in i-gel group, insertion time was found to be lower $(9.5 \mathrm{sec} \pm 0.7 \mathrm{SD})$ as compared to patients in LMA group (10.67sec $\pm 1.6 \mathrm{SD}$ ) $(p=0.02)$. Hayashi et al reported that LMA classic ${ }^{T M}$ had significant higher duration of insertion as compared to igel.22 Atef et al reported significant difference in median insertion time of i-gel and LMA with significantly lower time in i-gel group (16 seconds). Moreover, they reported that no cuff inflation was required by patients in i-gel group. They did not require any introducer and the device could be easily pushed into place. ${ }^{16}$

An insignificant difference between heart rate, systolic and diastolic B.P and mean arterial pressure in both groups was found in this study. Atef et al reported that LMA was associated with significant increase in heart rate and blood pressure $(p=0.01) .{ }^{23}$ However, Ali et al conducted a similar study in Lahore and reported no significant difference in hemodynamic parameters after one minute of device insertion in both i-gel and LMA group ( $p>0.05){ }^{24}$

This study was conducted at a single center that limits generalizability of the study. Furthermore, air way placement position was not assessed by flexible intubating fiberscope.

\section{Conclusion}

l-gel supraglottic device is a successful alternative option in terms of ease of insertion and less hemodynamic response as compared to laryngeal mask airway during general anesthesia. Surgeons and anesthesiologists should be very careful during application of these devices to avoid upper airway obstruction. Further research is required to evaluate minute details regarding efficacy of i-gel and LMA.

\section{References}

1. Janjua S, Adnan A, Zaidi AH, Bilal MS, Afridi JA. Tracheomalacia as an unusual cause of upper airways obstruction leading to cardiac arrest. Pak. Armed Forces med. J. 2015; 65(5): 714-5.

2. Wong $P$, Wong J, Mok MUS. Anaesthetic management of acute airway obstruction. Singapore Med J. 2016; 57(3): 110-7. Doi: 10.11622/smedj.2016050

3. Cook T.M, Davis M.S.R. Complications and failure of airway management. BJA. 2012; 109(1): i68-i85. Doi: 10.1093/bja/aes393.

4. Gavel G, Walker RW. Laryngospasm in anaesthesia. Contin Educ Anaesth Crit Care Pain. 2014; 14(2): 4751. Doi: doi:10.1093/bjaceaccp/mkt031

5. Siddiqui AS, Dogar SA, Lal S, Akhtar S, Khan FA. Airway management and postoperative length of hospital stay in patients undergoing head and neck cancer surgery. J Anaesthesiol Clin Pharmacol. 2016; 32(1): 49-53. Doi: 10.4103/0970-9185.173341

6. Polat R. Aydin B.G, Ergil J, Sayin M, Kokulu T, Ozturk I. Comparison of the i-gel ${ }^{\mathrm{TM}}$ and the Laryngeal Mask Airway Classic $^{\mathrm{TM}}$ in terms of clinical performance. Braz J Anesthesiol . 2015; 65(5): 343-348. Doi: 10.1016/j.bjane.2014.02.009

7. Batuwitage B, Charters P. Postoperative management of the difficult airway. BJA Educ. 2017; 17(7): 235-41. Doi: 10.1093/bjaed/mkw077

8. Chauhan G, Nayar P, Seth A, Gupta K, Panwar M, Agrawal N. Comparison of clinical performance of the I-gel with LMA. ProSeal. J Anaesthesiol Clin Pharmacol. 2013; 29(1): 56-60. Doi: 10.4103/09709185.105798

9. Singh J, Yadav MK, Marahatta SB, Shrestha BL. Randomized crossover comparison of the laryngeal mask airway classic with i-gel laryngeal mask airway in the management of difficult airway in post burn neck contracture patients. Indian J Anaesth. 2012; 56(4): 348-52. Doi: 10.4103/0019-5049.100815.

10. Pratheeba N, Ramya GS, Ranjan RV, Remadevi R. Comparison of $\mathrm{i}$-gel $\mathrm{T}^{\mathrm{TM}}$ and laryngeal mask airway Classic $^{T M}$ in terms of ease of insertion and hemodynamic response: A randomized observational study. Anesthesia, Essays and Researches. 2016; 10(3): 521. Doi: 10.4103/0259-1162.180780

11. Revi N, Harikishore, Puthur B, Ershad. A comparative study on cardiovascular response and ease of insertion in classical laryngeal mask airway, ProSeal laryngeal mask airway and l-gel during surgery under 
general anaesthesia. J Evid Based Med Healthcare. 2015; 2(20): 3039-46.

12. Radhika KS, Sripriya R, Ravishankar M, Hemanth Kumar VR, Jaya V, Parthasarathy S. Assessment of suitability of i-gel and laryngeal mask airway-supreme for controlled ventilation in anesthetized paralyzed patients: A prospective randomized trial. Anesth Essays Res. 2016; 10(1): 88-93. Doi: doi: 10.4103/0259-1162.167849

13. Hashemian .R.M.S, Nouraei N, Razavi S. S, Zaker E, Jafari A, Eftekhari $P$ et al. Comparison of $\mathrm{i}-\mathrm{ge} \mathrm{I}^{\mathrm{TM}}$ and laryngeal mask airway in anesthetized paralyzed patients. Int J Crit IIIn Inj Sci. 2014; 4(4): 288-292. Doi: 10.4103/2229-5151.147520

14. Sakpal Vijay Tushar. Sample size estimation in clinical trial. Prespect Clin Res. 2010; 1(2): 67-69. PMID: 21829786

15. Saran S, Mishra SK, Badhe AS, Vasudevan A, Elakkumanan LB, Mishra G. Comparison of i-gel supraglottic airway and LMA-ProSeal ${ }^{\mathrm{TM}}$ in pediatric patients under controlled ventilation. J Anaesthesiol Clin Pharmacol. 2014;30(2):195-8. Doi: 10.4103/0970-9185.130013

16. Helmy AM, Atef HM, El-Taher EM, Henidak AM. Comparative study between I-gel, a new supraglottic airway device and classical laryngeal mask airway in anaesthetized spontaneously ventilated patients. Saudi J Anaesth. 2010; 4(3): 131-6. Doi: 10.4103/1658-354X.71250

17. Reza Hashemian SM, Nouraei N, Razavi SS, Zaker $E$, Jafari $A$, Eftekhari $P$, et al. Comparison of $\mathrm{i}$-gel ${ }^{\mathrm{TM}}$ and laryngeal mask airway in anesthetized paralyzed patients. Int J Crit IIIn Inj Sci. 2014; 4(4): 288-92. Doi: 10.4103/2229-5151.147520

18. An J, Nam SB, Lee JS, Lee J, Yoo H, Lee HM, et al. Comparison of the i-gel and other supraglottic airways in adult manikin studies: Systematic review and metaanalysis. Medicine. 2017; 96(1): e5801. Doi: 10.1097/MD.0000000000005801
19. Kapoor S, Jethava D.D, Gupta P, Jethava D, Kumar A. Comparison of supraglottic devices i-gel ${ }^{\circledR}$ and LMA Fastrach ${ }^{\circledR}$ as conduit for endotracheal intubation. IJA. 2014;58(4): 397-402. Doi: 10.4103/00195049.138969

20. Fujiwara A, Komasawa N, Nishihara I, Miyazaki S, Tatsumi S, Nishimura W, et al. Muscle relaxant effects on insertion efficacy of the laryngeal mask ProSeal ${ }^{\circledR}$ in anesthetized patients: a prospective randomized controlled trial. J Anesth. 2015; 29(4): 580-4. Doi: 10.1007/s00540-015-1982-3

21. Acharya R. Dave N.M. Comparison between i-gel airway an the proseal laryngeal mask airway in pediatric patients undergoing general anesthesia. PACCJ. 2016; 4(2): 97-102. Doi: doi:10.14587/paccj.2016.20

22. Hayashi K, Suzuki A, Kunisawa T, Takahata $O$, Yamasawa $Y$, Iwasaki $H$. [A comparison of the singleuse i-gel with the reusable laryngeal mask airway Proseal in anesthetized adult patients in Japanese population]. Masui. 2013; 62(2): 134-9. PMID: 23479911

23. Atef HM, Fattah SA, Gaffer ME, Al Rahman AA. Perfusion index versus non-invasive hemodynamic parameters during insertion of i-gel, classic laryngeal mask airway and endotracheal tube. Indian $\mathrm{J}$ Anaesth. 2013; 57(2): 156-62. Doi: 10.4103/00195049.111843

24. Ali A, Ali L, Sheikh NA, Siddique SA. Airway device; Comparison of I-gel supraglotic with laryngeal mask airway for ease of insertion. Professional Med J Dec. 2010; 17(4): 643-7. 